\title{
The Comfor: an instrument for the indication of augmentative communication in people with autism and intellectual disability
}

\author{
I. Noens,' I. van Berckelaer-Onnes,' R. Verpoorten² \& G. van Duijn' \\ I University of Leiden, Faculty of Social and Behavioural Sciences, Clinical Child and Adolescent Studies, Leiden, the Netherlands \\ 2 Viataal, the Netherlands
}

\begin{abstract}
Background The ComFor (Forerunners in Communication) is an instrument to explore underlying competence for augmentative communication. More specifically, it measures perception and sense-making of non-transient forms of communication at the levels of presentation and representation. The target group consists primarily of individuals with autism and intellectual disability (ID) without or with only limited verbal communication. The ComFor is suitable for children and adults with a developmental level between 12 and 60 months. This paper describes the theoretical framework and structure of the ComFor, the results of a study on its psychometric properties and its clinical uses.

Method The ComFor was tested on a sample of 623 children and adults from the Netherlands and Flanders: a group with autism and ID $(n=3$ IO); a group with ID without autism $(n=\mathrm{I} 74)$; and a control group of typically developing children $(n=\mathrm{I} 39)$.
\end{abstract}

Correspondence: Ilse Noens, University of Leiden, Faculty of Social and Behavioural Sciences, Clinical Child and Adolescent Studies, PO Box 9555, 2300 RB Leiden, the Netherlands (e-mail: noens@fsw.leidenuniv.nl).

(C) 2006 Blackwell Publishing Ltd
Results The data generally support the reliability and validity of the ComFor. Internal consistency, inter-rater and test-retest reliability were found to be good. Construct validity (internal structure, convergent and divergent patterns) was established in different ways. The criterion-related validity has yet to be established, as predictive data are not available at the moment.

Conclusion Taken together, the results indicate that the ComFor is a promising instrument to explore underlying competence for augmentative communication. Areas for future research are outlined and the clinical relevance is discussed.

Keywords augmentative communication, autism, diagnostic instrument, intellectual disability

\section{Introduction}

Many studies have shown that intellectual disability ${ }^{1}$ (ID) is common among individuals with an autism spectrum disorder (ASD), especially those with the

\footnotetext{
${ }^{1}$ The UK term 'intellectual disability' refers to the international ICD-Io/DSM-IV term 'mental retardation'.
} 
core autistic disorder (AD). Nevertheless, the number of publications on treatment of children and adults with ASD and ID is very limited. Most of the specific treatment programmes focus on higherfunctioning individuals with ASD; lower-functioning individuals usually have to rely on intervention within the care system for people with ID. However, at the level of cognition, there is a huge difference between ID and ASD. People with ID without ASD primarily display a general cognitive delay, whereas people with ASD show a specific cognitive deviance. Individuals with ASD and ID suffer from a dual handicap; therefore, they need specific interventions (Van Berckelaer-Onnes I996; Kraijer I997; Ghaziuddin 2000; Jordan 200I).

Discussions on cognitive deviance in ASD concentrate mainly around theory of mind, executive functions and central coherence (Hill \& Frith 2003). Central coherence is the natural tendency to process incoming stimuli globally and in context, pulling information together for higher-level meaning (Frith I989, 2002). People with ASD show a weak drive for central coherence: they have a preference for detailfocused processing and a relative incapacity to make use of meaning. In low-functioning individuals with ASD, the central coherence account offers the best potential for explaining the behavioural features, because problems in theory of mind or executive functioning can also be the result of ID. Furthermore, the central coherence account has far-reaching consequences for education and intervention (Noens \& Van Berckelaer-Onnes 2004).

The communication problems of people with ASD can be conceptualized from the viewpoint of a weaker drive for central coherence (Noens \& Van BerckelaerOnnes 2005). Communication requires extremely rapid and multi-modal processing of auditory and visual stimuli which are transient and temporally organized (Fay \& Schuler I980; Prizant \& Schuler I987; Wetherby et al. 2000). The weaker drive for central coherence makes effective sense-making very complicated. Approximately one-third (Bryson I996) to onehalf (Lord \& Paul I997) of those individuals with the core AD do not develop enough natural speech to meet their daily communication needs; most of them also suffer from ID. Even among those with functional speech, understanding is usually more limited than what one would expect on the basis of their expressive vocabulary (Lord \& Paul 1997; Schuler et al. 1997).

\section{Augmentative communication}

'Augmentative communication' refers to the totality of strategies and techniques to augment communication, in addition to natural gestures, vocalizations or speech of the individual (Noens \& Van BerckelaerOnnes 2004). As a supportive strategy tailored to individuals with ASD and ID, it involves not only expression but above all comprehension (Light et al. I998). Two core questions need to be addressed: (I) what is the most suitable form of augmentation? and (2) at which level of sense-making can the means chosen be offered?

With respect to the form of augmentation, Fay \& Schuler (1980) indicated that individuals with ASD are much more successful with non-transient, spatially organized means: objects, pictures and written text. As far as the level of sense-making is concerned, one can roughly distinguish four levels: sensation, presentation, representation and meta-representation (Verpoorten I996).

At the level of sensation, sensory experiences are essential. A plastic cup, for example, is no more than a configuration of stimuli. When the cup is offered regularly, the stimuli can appear familiar, which is very important for a feeling of safety. However, there is neither functional nor referential meaning. At this level, it is important that the environment and all activities be highly structured. Space should be organized very functionally and caregivers should stick to fixed routines and activity scenarios.

At the level of presentation, one perceives information within a concrete context. The individual now understands the functional meaning of the cup, on the condition that it actually contains a drink; the meaning has to be literally 'present'. Life becomes predictable within the here and now of the actual situation.

The level of representation is achieved when symbolic skills exist. The word 'cup' represents the object. If individuals do not speak but understand that a gesture, an object or a picture refers to drinking even when the drink itself is not in sight, the level of representation has been reached too. The individual then understands the hidden meaning, the reference or symbolic function. Representation implies certain awareness that the symbol and the referent are not identical but two clearly separate entities (Bates 
I. Noens et al. - The ComFor

I979). The development of object permanence is indispensable to reach the level of representation. Communication at this level offers a grip on the future. Predictability outside the here and now of the actual situation develops.

At the level of meta-representation, the information behind the primary information is perceived. It concerns a meaning detached from the first representation. When, for example, someone 'won a cup', the cup does not refer to something containing a drink (the primary meaning) but to a victory. Human language is full of meta-representations, such as idioms and metaphors.

All people with ASD have difficulty reaching the level of meta-representation, but in the event of co-morbidity with ID, even the transitions from sensation to presentation and from presentation to representation are not always made (Noens \& Van Berckelaer-Onnes 2004). Determination of the level of sense-making is crucial for individualized interventions.

\section{The ComFor}

The ComFor (Dutch version; Verpoorten et al. 2004; English version; R. Verpoorten et al. in press) is a clinical instrument to obtain a precise indication of individualized communicative interventions, in particular augmentative communication. It addresses the two questions considered in the previous discussion: (I) what is the most suitable form of augmentation? and (2) at which level of sense-making can the means chosen be offered? More specifically, the ComFor measures perception and sense-making with respect to nontransient forms of communication at the levels of presentation and representation. The level of sensation is not directly assessed. However, communication should be realized at the level of sensation if an individual does not meet the conditions for presentation. The ComFor thus only offers a rough indication of augmentative communication at the level of sensation; further assessment will be necessary. The level of meta-representation is not considered, as people with ASD and ID generally do not reach this level (Noens \& Van BerckelaerOnnes 2004).

The ComFor consists of two levels with a total of five series and 36 items (see Appendix). Level I con- cerns tasks at the level of presentation, level 2 at the level of representation. The script of the test activity is very straightforward: each item is organized as a sorting task.

At the level of presentation, identical objects or pictures have to be sorted according to shape, colour, matter and size. The tasks can thus be resolved on the basis of concrete, literally perceptible features. The presentation level comprises three series: I, 2 and 3. Series I (six items) is the socalled learning series, in which sorting is trained step by step. In order to understand the script, one must perceive the association between objects.

Assembling procedures are used to build up towards sorting in open baskets. In the beginning of the series, a specific design of the destination supports the association (e.g. fitting a block into the square hole in a closed box). The supporting design fades gradually, requiring a more complex objectobject association (e.g. all identical spoons in an open basket). As such, it no longer involves assembling but instead sorting - or matching - identical objects. In series 2 (seven items), concrete objects have to be sorted according to shape, colour, matter and size. Series 3 (Io items) involves the sorting of pictures (photographs, line drawings, pictograms and written text).

At the level of representation, non-identical objects or pictures have to be sorted on the basis of sense-making beyond the concrete, literally perceptible features (e.g. categorizing different balls, dolls and cars). It only concerns primary and functional meanings. The representation level consists of two series: 4 and 5. Series 4 (five items) has to be sorted within one form (objects to objects or photographs to photographs). Series 5 (eight items) involves sorting of different forms (objects to photographs or vice versa; objects to pictograms or vice versa; photographs to written text or vice versa).

The target group of the ComFor consists of children and adults with ASD without or with only limited verbal communication. The scope varies from a (psychomotor) developmental level of about I 2 months up to about 60 months. In the study reported in this paper, only participants with $\mathrm{AD}$ (DSM-IV, 299.00) were included; however, the ComFor is applicable to the broader group of individuals with ASD. 
I. Noens et al. • The ComFor

\section{Method}

\section{Participants}

The total sample consisted of 623 individuals from a Dutch-speaking region (Netherlands and Flanders) with a developmental level between I 2 and 60 months on the domain of daily living skills, measured with the Dutch version of the Vineland Screener (S. S. Sparrow, A. S. Carter \& D. Cicchetti, unpublished manuscript). The sample comprised three groups: (I) a group of children and adults with $\mathrm{AD}$ and ID ( $n=3$ IO); (2) a group of children and adults with ID without $\mathrm{AD}(n=\mathrm{I} 74)$; and a control group of typically developing (TD) children $(n=\mathrm{I} 39)$. A smaller group was selected for the study on test-retest reliability $(n=48)$ and inter-rater reliability $(n=\mathrm{I} 7 \mathrm{I})$. For evaluation of the convergent validity, the Communication Profile-Z (CPZ) (Willems \& Verpoorten I996) was administered to a subsample $(n=40)$.

The control group was selected via regular day care centres and primary schools in the Netherlands. The children and adults in the clinical groups were recruited through institutions and special schools for people with ID in the Netherlands and Flanders. Individuals with additional sensory or motor disabilities (following ICD-Io; World Health Organization I994) were excluded. Sensory disabilities have a strong impact on the perceptual process that the ComFor is trying to capture, and motor disabilities interfere with the administration. Data were provided by the institutions and special schools of the participants.

The composition of the subsamples was as homogeneous as possible. In the AD subsample, only clients with AD (DSM-IV, 299.00) were included. In accordance with Fombonne (I992), Lord et al. (1997) and Kraijer (2000), who advised using the level of daily living skills as matching variable to compare people with ID with and without AD, Table I shows the results for the domain daily living skills of the Vineland Screener. The means of the groups with and without $\mathrm{AD}$ (38.98 vs. 4I.50 months) are close to each other but still differ considerably $(P<0.00 \mathrm{I})$. By selecting a child with AD for each child without $\mathrm{AD}$ and an adult with $\mathrm{AD}$ for each adult without $\mathrm{AD}$ at the same level (difference maximum I5 days), two comparable groups of I55 clients each were established (Table 2).

\section{Other measures}

\section{Vineland Screener o-6}

The level of functioning of the participants was determined with the Vineland Screener, a quick, reliable and valid measure of personal and social sufficiency, specifically developed for research purposes (S. S. Sparrow, A. S. Carter \& D. Cicchetti, unpublished manuscript). The Screener o-6 (a combination of American versions 0; 0-2, I I and 3; 0-5, II) was recently adapted and standardized for a Dutch sample (University of Leiden, in prep.). The reliability and validity of the American version of the Vineland Adaptive Behavior Scales were studied and described extensively. With respect to the Dutch Vineland Screener 0-6, all coefficients of inter-rater reliability, test-retest reliability and internal consistency are 0.89 or higher.

Table I Sample characteristics

\begin{tabular}{|c|c|c|c|c|c|c|c|}
\hline \multirow[b]{2}{*}{ Subsample } & \multirow[b]{2}{*}{$n$} & \multicolumn{2}{|c|}{ CA (months) } & \multicolumn{2}{|c|}{ DLS (months) } & \multicolumn{2}{|c|}{ Gender (\%) } \\
\hline & & M & SD & $\mathbf{M}$ & SD & Male & Female \\
\hline \multicolumn{8}{|l|}{ ID } \\
\hline With AD & 310 & 199.81 & 166.32 & 38.98 & 12.09 & 79.4 & 20.6 \\
\hline Without AD & 174 & 233.51 & 188.92 & 41.50 & 12.09 & 58.6 & 41.4 \\
\hline Sub-total & 484 & 211.98 & 175.37 & 39.88 & 12.14 & 71.9 & 28.1 \\
\hline TD (control) & 139 & 35.33 & 12.25 & 36.35 & 14.35 & 58.3 & 41.7 \\
\hline Total & 623 & 172.66 & 171.29 & 39.29 & 12.59 & 68.9 & 31.1 \\
\hline
\end{tabular}

CA, chronological age; DLS, developmental level for daily living skills; ID, intellectual disability; AD, autistic disorder; TD, typically developing.

(C) 2006 Blackwell Publishing Ltd, fournal of Intellectual Disability Research 50, 62 I-632 
I. Noens et al. • The ComFor

Table 2 Characteristics of the two paired subsamples

\begin{tabular}{|c|c|c|c|c|c|c|c|}
\hline \multirow[b]{2}{*}{ Subsample } & \multirow[b]{2}{*}{$n$} & \multicolumn{2}{|c|}{ CA (months) } & \multicolumn{2}{|c|}{ DLS (months) } & \multicolumn{2}{|c|}{ Gender (\%) } \\
\hline & & M & SD & $\mathbf{M}$ & SD & Male & Female \\
\hline With AD & 155 & 204.22 & 157.13 & 41.32 & 11.90 & 79.4 & 20.6 \\
\hline Without AD & 155 & 221.88 & 185.64 & 41.34 & 11.89 & 58.7 & 41.3 \\
\hline Total & 310 & 213.08 & 171.97 & 41.33 & 11.88 & 69.0 & 31.0 \\
\hline
\end{tabular}

$\mathrm{CA}$, chronological age; DLS, developmental level for daily living skills; $\mathrm{AD}$, autistic disorder.

\section{Communication Profile- $Z$}

A common method to demonstrate validity is to compute correlations with instruments that measure the same construct. As yet, there is no valid instrument with the same objective as the ComFor. To our knowledge, the only instrument that includes a few comparable items is the CPZ (Willems \& Verpoorten I996), a Dutch instrument that collects information on communication forms used (expressive) and understood (receptive) by people with ID. The CPZ consists of a questionnaire and a test. In the ComFor validity study, only the latter was used. The test consists of four sub-scales: receptive non-vocal, receptive vocal, expressive non-vocal, and expressive vocal. The psychometric properties of the CPZ have been studied in detail (Willems I996); reliability and validity are high (Evers et al. 2000).

The ComFor and the CPZ have been operationalized differently. First, the CPZ is broader than the ComFor, which focuses exclusively on receptive, non-vocal perception. Second, the CPZ does not distinguish explicitly between presentation and representation; most of its items are at the level of representation.

\section{Procedure}

The primary caregivers of the participants (parents or professionals) were asked to fill out the Vineland Screener o-6. Subsequently, the ComFor was administered by research assistants from the University of Leiden. Their training consisted of a ComFor course, dealing with test procedure and administration pitfalls. Subsequently, they had to carry out a test administration, which was recorded and discussed afterwards. The whole process of data collection was supervised by one of the researchers. All administrations were video-recorded to enable repeat scoring for reliability purposes.

\section{Data analysis}

All data were entered into SPSS I0.0. As far as reliability is concerned, the internal consistency of the series and levels of the ComFor was established with Cronbach's coefficient alpha. To establish the inter-rater reliability, Cohen's kappas were computed for each of the items. With respect to the test-retest reliability, the ComFor was administered twice at an interval of 2 weeks. Pearson's $r$ and Spearman's $r$ were computed.

The design of the validity study is more complicated. Validity can be judged according to different aspects: content, construct and criterion-related validity (Carmines \& Zeller 1994; Evers 200I). The content validity is not dealt with explicitly in this study, but is underpinned by a review of literature and a careful process of operationalization, selection and categorization of the items, as described in the Comfor manual. Construct validity is the primary focus of attention in this paper and warranted in different ways.

First, the internal structure of the ComFor was established by principal component analysis of the ComFor results of the subsample of people with $\mathrm{AD}$ and ID. The decision to conduct the analysis primarily on this subsample and not the total sample is based on the fact that operationalization of the ComFor is autism-specific. An oblique rotation had to be performed: the levels of presentation and representation are not two independent factors (as presupposed using orthogonal rotation), but correlate with each 
other. As outlined above, presentation precedes representation developmentally.

Second, convergent and divergent correlation patterns were identified. To that end, the results for participants with and without AD were compared, and the relationship with other instruments and variables was studied. The results of the comparison between the mean scores of the ID subsamples with and without $\mathrm{AD}$ will be described in detail in a separate paper (I. Noens \& I. A. Van Berckelaer-Onnes, in preparation). Within this paper, we will confine ourselves to the main points.

\section{Results}

\section{Internal consistency}

If an instrument is used for decisions that are irreversible in the short term, the reliability has to be 0.90 at least, while for reversible decisions a coefficient of 0.80 is sufficient; for use at the group level, coefficients above 0.70 are judged 'good' (Nunnally \& Bernstein 1994). Considering the objective of the ComFor - indication of augmentative communication, a reversible decision - the data in Table 3 support the internal consistency of the ComFor.

\section{Inter-rater reliability}

The inter-rater reliability is very high: the mean kappa is 0.95 ( $n=\mathrm{I} 7 \mathrm{I})$. For item A3, kappa is 0.80 ; all other kappas are above 0.9I. Qualitative analysis of the data on item $A_{3}$ reveals that raters usually disagree on the amount of physical help that may be offered to assemble the rings in the box.

As far as these high kappas are concerned, it is important to keep in mind that all raters passed the training process discussed above. Furthermore, the ComFor rating is dichotomous. As soon as one object or card has been sorted incorrectly, the whole item has to be rated as incorrect. Consequently, there cannot be much controversy between raters.

\section{Test-retest reliability}

The scores on the ComFor are relatively stable at an interval of 2 weeks (Table 4). For the subsample with $\mathrm{AD}$ and ID, however, there are striking differences between the series. Qualitative analysis of the

Table 4 Test-retest reliability (Spearman's $r$ ) of the ComFor

\begin{tabular}{llll}
\hline ComFor & $\begin{array}{l}\text { Total } \\
(\boldsymbol{n}=\mathbf{4 8})\end{array}$ & $\begin{array}{l}\text { With AD } \\
(\boldsymbol{n}=\mathbf{2 2})\end{array}$ & $\begin{array}{l}\text { Without AD } \\
(\boldsymbol{n}=\mathbf{2 6})\end{array}$ \\
\hline Series 1 & 0.95 & 0.95 & 0.95 \\
Series 2 & 0.93 & 0.93 & 0.94 \\
Series 3 & 0.90 & 0.81 & 0.97 \\
Series 4 & 0.87 & 0.81 & 0.89 \\
Series 5 & 0.91 & 0.88 & 0.86 \\
Presentation & 0.97 & 0.97 & 0.99 \\
Representation & 0.91 & 0.84 & 0.91 \\
Total & 0.98 & 0.98 & 0.98 \\
\end{tabular}

$\mathrm{AD}$, autistic disorder.

Table 3 Internal consistency of the ComFor (Cronbach's alpha)

ID

\begin{tabular}{|c|c|c|c|c|c|}
\hline \multirow[b]{2}{*}{ ComFor sub-scale } & \multirow[b]{2}{*}{$\begin{array}{l}\text { Total } \\
(n=623)\end{array}$} & & \multirow[b]{2}{*}{$\begin{array}{l}\text { TD } \\
(n=139)\end{array}$} \\
\hline & & $\begin{array}{l}\text { With AD } \\
(n=3 \mid 0)\end{array}$ & $\begin{array}{l}\text { Without AD } \\
(n=174)\end{array}$ & $\begin{array}{l}\text { Sub-total } \\
(n=484)\end{array}$ & \\
\hline Series I (6 items) & 0.83 & 0.87 & 0.80 & 0.84 & 0.80 \\
\hline Series 2 (7 items) & 0.91 & 0.93 & 0.90 & 0.92 & 0.87 \\
\hline Series 3 ( 10 items) & 0.93 & 0.94 & 0.91 & 0.93 & 0.90 \\
\hline Series 4 (5 items) & 0.85 & 0.87 & 0.83 & 0.86 & 0.80 \\
\hline Series 5 (8 items) & 0.92 & 0.94 & 0.90 & 0.92 & 0.90 \\
\hline Presentation ( 23 items) & 0.95 & 0.96 & 0.94 & 0.95 & 0.93 \\
\hline Representation (13 items) & 0.94 & 0.95 & 0.92 & 0.94 & 0.92 \\
\hline
\end{tabular}

ID, intellectual disability; $\mathrm{AD}$, autistic disorder; TD, typically developing.

(C) 2006 Blackwell Publishing Ltd, fournal of Intellectual Disability Research 50, 62 I-632 
I. Noens et al. - The ComFor

individual data at the item level reveals two tendencies: (I) there is a certain learning effect; and (2) the individual's top scores are less stable. The latter is clinically highly relevant. The indication of augmentative communication thus has to make allowance for an uncertainty margin at the top of an individual's potential. For a 'safe' choice of augmentative communication, it is recommended to start somewhat below the top level, as will be discussed later.

\section{Comparison of the two paired clinical subsamples}

The group with AD shows a greater difference between presentation and representation scores than the group without AD (see 'subtraction' in Table 5, $P<0.0$ I). The variance within both subsamples is high.

\section{Principal component analysis}

Principal component analysis was conducted on the ComFor results of people with $\mathrm{AD}$ and ID $(n=3 \mathrm{IO})$. The three component solution accounts for $67.5 \%$ of the total variance. Examination of the unrotated components indicates that the first component accounts for $5 \mathrm{I} .2 \%$ of the variance (Eigenvalue $=18.43$ ), the second for $10.6 \%($ Eigenvalue $=3.83$ ) and the third for $5.7 \%$ (Eigenvalue $=2.06$ ). Table 6 shows the item loadings for the three components

Table 5 Comparison between the two paired subsamples

\begin{tabular}{|c|c|c|c|c|c|}
\hline \multirow[b]{2}{*}{ ComFor } & \multicolumn{2}{|c|}{$\begin{array}{l}\text { With AD } \\
(n=I 55)\end{array}$} & \multicolumn{2}{|c|}{$\begin{array}{l}\text { Without } \\
\text { AD } \\
(n=155)\end{array}$} & \multirow[b]{2}{*}{$t($ d.f. $=308)$} \\
\hline & $\mathbf{M}$ & SD & $\mathbf{M}$ & SD & \\
\hline Series I & 5.59 & I.I7 & 5.71 & 0.79 & -1.03 \\
\hline Series 2 & 4.52 & 2.80 & 3.94 & 2.60 & 0.89 \\
\hline Series 3 & 4.67 & 4.01 & 3.59 & 3.33 & 2.59 \\
\hline Series 4 & 1.69 & 1.90 & 1.20 & 1.61 & 2.45 \\
\hline Series 5 & 3.08 & 3.10 & 3.14 & 2.76 & -0.17 \\
\hline Presentation & 14.79 & 7.12 & 13.24 & 6.08 & 2.06 \\
\hline Representation & 4.77 & 4.84 & 4.34 & 4.12 & 0.85 \\
\hline Subtraction & 10.01 & 4.00 & 8.90 & 3.09 & $2.75^{*}$ \\
\hline Total & 19.56 & 11.50 & 17.58 & 9.92 & 1.62 \\
\hline
\end{tabular}

$* P<0.0$ I.

$\mathrm{AD}$, autistic disorder. after oblique rotation (delta $=0$; structure matrix). Item loadings are a gauge of the substantive power of a given variable to a given factor (Field 2000); given the sample size $(n=310)$, the loading should be higher than 0.298 to be important (Stevens I992).

The second component can best be described as 'presentation - assembling', as almost all items of series I (presentation level; 'assembling objects') are loading high $(>0.80)$ on it. The items loading high on

Table 6 Item loadings ${ }^{\star}$ for three component solution after principal component analysis with oblique rotation on the subsample with $\mathrm{AD}$ $(n=3 \mathrm{IO})$

\begin{tabular}{|c|c|c|c|}
\hline Item & Component & Component & Component \\
\hline Al & - & 0.81 & - \\
\hline $\mathrm{A} 2$ & - & 0.90 & - \\
\hline A3 & - & 0.90 & - \\
\hline B & - & 0.84 & -0.43 \\
\hline C & - & 0.69 & -0.59 \\
\hline D & - & 0.60 & -0.64 \\
\hline I & 0.37 & 0.41 & $-0.8 I$ \\
\hline 2 & 0.41 & 0.35 & -0.85 \\
\hline 3 & 0.42 & 0.32 & -0.85 \\
\hline 4 & 0.48 & - & -0.90 \\
\hline 5 & 0.58 & - & -0.83 \\
\hline 6 & 0.64 & - & -0.82 \\
\hline 7 & 0.50 & - & -0.70 \\
\hline 8 & 0.55 & - & -0.88 \\
\hline 9 & 0.56 & - & -0.82 \\
\hline 10 & 0.53 & - & -0.86 \\
\hline II & 0.73 & - & -0.77 \\
\hline 12 & 0.76 & - & -0.72 \\
\hline 13 & 0.73 & - & -0.78 \\
\hline 14 & 0.74 & - & -0.58 \\
\hline 15 & 0.78 & - & -0.50 \\
\hline 16 & 0.81 & - & $-0.5 I$ \\
\hline 17 & 0.72 & - & -0.35 \\
\hline 18 & 0.75 & - & -0.64 \\
\hline 19 & 0.79 & - & -0.67 \\
\hline 20 & 0.73 & - & -0.55 \\
\hline 21 & 0.82 & - & -0.48 \\
\hline 22 & 0.63 & - & - \\
\hline 23 & 0.71 & - & -0.75 \\
\hline 24 & 0.75 & - & -0.72 \\
\hline 25 & 0.80 & - & -0.74 \\
\hline 26 & 0.87 & - & -0.69 \\
\hline 27 & 0.84 & - & -0.64 \\
\hline 28 & 0.86 & - & -0.63 \\
\hline 29 & 0.65 & - & -0.31 \\
\hline 30 & 0.59 & - & - \\
\hline
\end{tabular}

* Loadings $<0.30$ are not displayed.

(C) 2006 Blackwell Publishing Ltd, fournal of Intellectual Disability Research 50, 62 I-632 
I. Noens et al. - The ComFor

the third component are all items from series 2 and 3 (presentation level: 'sorting objects' and 'sorting pictures'). The third component can thus best be described as 'presentation - sorting'. Item D, whereby balls and blocks have to be fitted into a closed box, while spoons have to be sorted in an open box, is at the borderline of assembling and sorting. The items loading high on the first component are mostly items from series 4 and 5 (representation level; 'sorting within one form' and 'sorting with different forms'). The first component is therefore best described as 'representation - sorting'.

The second component is clearly distinguishable from the first and third components, although the easiest items of series 2 still load somewhat on the second component. This is not surprising, because assembling is a precursor of sorting. All items of series 2, 3, 4 and 5 load more or less on the first and third components. The importance of the third component decreases as the importance of the first component globally increases, which indicates that the levels of presentation and representation should be conceptualized as two merging levels of sense-making.

The internal structure of the ComFor is generally consistent with the three component solution after oblique rotation. However, for three items of series 3 (items II-I3) the loading is substantial on both the first and the third component, and for four items (items I4-I7) the loading is even higher on the first than on the third component. For people with AD, these are the most difficult items at the presentation level (I. Noens \& I. A. Van Berckelaer-Onnes, in preparation). Conversely, for items 23 and 24, the easiest items at the representation level, the loading on the third component is also substantial. There seems to be a kind of transition area from presentation to representation.

If the items of series I are excluded, principal component analysis yields a two component solution; after oblique rotation the item loadings on the components 'presentation - sorting' and 'representation - sorting' remain almost exactly the same. Analyses on the other subsamples and the total sample for all the items also result in three component solutions; after oblique rotation, however, the internal structure of the ComFor is less recognizable. The first series can still be distinguished, but the distinction between presentation and representation fades. This means that the dissociation between presentation and representation is autism-specific.

\section{Relationship with other instruments}

The CPZ was administered to 20 participants with ID and AD and 20 participants with ID without AD. The correlation (Pearson's $r$ ) between the total scores of the ComFor and the CPZ is 0.6I $(P<0.0 \mathrm{I})$. In accordance with the different operationalizations of both instruments, the correlations with representation are stronger than those with presentation, nonvocal stronger than vocal, and receptively slightly stronger than expressively (Table 7).

The Vineland Screener o-6 was administered to all 623 participants. The correlation between the Vineland Screener and the ComFor is stronger for the TD subsample than for the ID subsamples (Table 8). The fact that the correlation with socialization is somewhat lower than with the other domains can possibly be explained by the fact that the operationalization of the ComFor takes the impairments of social interaction in people with $\mathrm{AD}$ into account. The ComFor is organized so strictly that use of the social skills of the participants is minimalized. On the other hand, one can argue that each test situation at least requires some social adaptation. It is important to note that the Vineland Screener is merely a screening instrument and cannot provide a differentiated picture of adaptive development.

\section{Relationship with other variables}

Gender and area of living are not expected to correlate with ComFor results, while type of care system

Table 7 Correlations (Pearson's $r$ ) between the ComFor and the $\mathrm{CPZ}(n=40)$

\begin{tabular}{lll}
\hline & Presentation & Representation \\
& & \\
\hline & & \\
Receptive, non-vocal & $0.65^{*}$ & $0.72^{*}$ \\
Receptive, vocal & $0.43^{*}$ & $0.53^{*}$ \\
Expressive, non-vocal & $0.60^{*}$ & $0.7 I^{*}$ \\
Expressive, vocal & 0.31 & 0.39 \\
& & \\
$* P<$ o.or. & & \\
$\mathrm{CPZ}$, Communication Profile-Z.
\end{tabular}


I. Noens et al. • The ComFor

Table 8 Correlation (Pearson's $r$ )* between the ComFor and the Vineland Screener

ID

\begin{tabular}{lllll}
\cline { 3 - 4 } Vineland Screener & $\begin{array}{l}\text { Total } \\
(\boldsymbol{n}=\mathbf{6 2 3})\end{array}$ & $\begin{array}{l}\text { With AD } \\
(\boldsymbol{n}=\mathbf{3 1 0})\end{array}$ & $\begin{array}{l}\text { Without AD } \\
(\boldsymbol{n}=\mathbf{1 7 4})\end{array}$ & $\begin{array}{l}\text { TD } \\
(\boldsymbol{n}=\mathbf{1 3 9})\end{array}$ \\
\hline Total & 0.71 & 0.74 & 0.70 & 0.82 \\
Communication & 0.64 & 0.68 & 0.57 & 0.82 \\
Daily living skills & 0.61 & 0.58 & 0.63 & 0.80 \\
Socialization & 0.45 & 0.54 & 0.52 & 0.68 \\
Motor skills & 0.66 & 0.66 & 0.61 & 0.77 \\
\hline
\end{tabular}

* All correlations are significant $(P<0.001)$.

ID, intellectual disability; $\mathrm{AD}$, autistic disorder; $\mathrm{TD}$, typically developing.

and amount of speech are well expected to exhibit correlation. Gender and area of living indeed prove not to correlate with ComFor results. With respect to type of care system, I88 participants of the ID subsample attend a school for children with ID (mostly moderate to severe ID), while I32 participants visit a day care for children with ID (mostly severe to profound ID). As expected, the children in school achieve significantly better ComFor results than those in a day care $[t(3 \mathrm{I} 8)=9.45, P<0.00 \mathrm{I}]$. Discriminant analysis of the ComFor data for all children with ID leads to a correct prediction of the type of care system in 74.I\% of cases. Analysis on the data for children with ID and AD only $(n=2 \mathrm{II})$ predicts type of care system correctly in $75.4 \%$ of cases.

One item of the Vineland Screener ('Says at least 50 recognizable words') was selected as a criterion for the amount of speech. This item refers to the use of words in daily life (not during the assessment), although one has to keep in mind that having a vocabulary of 50 words is not a guarantee for functional use. For 483 participants of the ID subsamples, it is known whether they say at least 50 recognizable words: 269 participants do, 2 I4 do not. The participants with at least 50 words achieve significantly better ComFor results $[t(48 \mathrm{I})=-\mathrm{I} 3.24$, $P<0.00 \mathrm{I})$. Discriminant analysis of the ComFor data for all the participants with ID leads to a correct prediction in $75.2 \%$ of the cases, whereas analysis on the data for participants with ID and AD only $(n=309)$ leads to a correct classification in $79.0 \%$ of the cases.

\section{Discussion}

\section{Directions for future research}

The data presented in this paper generally confirm the reliability and validity of the ComFor. At present, criterion-related validity has yet to be established. Many authors noted the difficulty of finding valid criteria, particularly for speech and communication. This applies - possibly even more strongly - to perception and sense-making. Therefore, indirect criteria had to be used: adaptive behaviour, the amount of speech and type of care system. However, all criteria are concurrent; data on predictive validity are not available yet.

Furthermore, it is important to remark that the ComFor was developed for people with ASD but that the study reported in this paper only included participants with the core AD. Future research will have to show whether the discrepancy found between scores at the presentation and representation levels also counts for people with related ASD. Possibly, the discrepancy is specific for particular subgroups. Longitudinal research into perception and sense-making in people with ASD is also of crucial importance.

\section{Clinical relevance}

Both the greater difference between presentation and representation scores in people with $\mathrm{AD}$ compared with people without $\mathrm{AD}$ and the fact that the internal structure of the ComFor seems to be $\mathrm{AD}$-specific lead to the hypothesis that AD is characterized by a qualitative difference in the development of percep- 
tion and sense-making, which pleads for specific intervention. If an individual has strong presentation skills at his or her disposal, he or she can compensate for weaker representation skills. In that respect, two specific strategies of augmentative communication were developed: assembling and matching (described in Noens \& Van Berckelaer-Onnes 2004; illustrated in Noens \& Van Berckelaer-Onnes 2002, a video production on augmentative communication for people with $\mathrm{AD}$ and ID). These two strategies correspond with the two non-representation components found by principal component analysis. Assembling refers to 'presentation - assembling'; matching refers to the association of two identical forms and can be considered 'presentation - sorting'. The term 'matching' was introduced to distinguish sorting at the presentation level from sorting at the representation level in clinical practice.

The aim of the ComFor is a clinical and individual indication of augmentative communication. The central question is what each individual succeeded in doing, and what went wrong. It is therefore a content-referenced interpretation, not a norm-referenced interpretation (Evers 200I). The individual profiling of positive scores within the series and the levels is indicative of specific interventions. Comparison of the results of an individual with those of others is not relevant in the context of the indication of augmentative communication. Generally, all positively scored items are useful for extrapolation to augmentative communication, while taking into consideration an uncertainty margin at the top of an individual's potential. There are two reasons to start somewhat below top level. First, the ComFor is administered within optimal conditions: a very structured situation with oneon-one guidance. The results obtained should thus be considered 'top scores'. From a developmental point of view, clinicians usually tend to start augmentative communication at top level, but it is important to keep in mind that the daily reality is usually more complicated. Augmentative communication should also offer support in less optimal situations, such as a crowded-group context or without individual guidance. A second reason to start below top level was mentioned in the section on test-retest reliability; qualitative analyses of individual data revealed some instability of the individual's top scores.
The ComFor answers two questions: (I) what are the most suitable means to augment communication? and (2) at which level of sense-making can the means chosen be offered? Concerning the form of augmentation, ComFor results indicate whether the form should be two or three dimensional; more specific requirements for each of the options are given. With respect to the level of sense-making, three general indications are possible: sensation, presentation (with distinction between assembling and matching) and representation.

The ComFor has proved to be a very valuable tool in clinical practice. The ComFor helps to determine which non-transient, spatial form of communication is the best fit, and at which level of sense-making the means chosen can be offered. Too often, people with $\mathrm{AD}$ and ID are confronted with symbol communication systems that they do not understand. Symbol communication systems (such as Picture Exchange Communication System) are only useful if the individual is able to make sense at the level of representation. Determination of the level of sense-making is of crucial importance. A level of approach that is too high can lead to severe challenging behaviour. If communication intervention is tuned into the individual needs, people with $\mathrm{AD}$ and ID will be less vulnerable.

\section{Acknowledgements}

The authors wish to thank all the participants and their caregivers, students and research assistants who took part in this study. The Effatha Guyot Group and the University of Leiden financed the study. This paper was submitted in part fulfilment of the first author's PhD Degree at the University of Leiden.

\section{References}

Bates E. (1979) Intentions, conventions, and symbols. In: The Emergence of Symbols: Cognition and Communication in Infancy (eds E. Bates, L. Benigni, I. Bretherton, L. Camaioni \& V. Volterra), pp. 33-68. Academic Press, New York.

Bryson S. E. (1996) Brief report: epidemiology of autism. Fournal of Autism and Developmental Disorders 26, I65-7.

Carmines E. G. \& Zeller R. A. (1994) Reliability and validity assessment. In: Basic Measurement (ed. M. S. LewisBeck), pp. I-59. Sage, London. 
I. Noens et al. - The ComFor

Evers A. (200I) The revised Dutch rating system for test quality. International fournal of Testing I, I55-82.

Evers A., Van Vliet-Mulder J. C. \& Groot C. J. (2000) Documentatie van tests en testresearch in Nederland [Documentation of tests and test research in the Netherlands]. Van Gorcum, Assen.

Fay W. H. \& Schuler A. L. (1980) Emerging language in autistic children. University Park Press, Baltimore, MD.

Field A. (2000) Discovering Statistics Using SPSS for Windows. Sage, London.

Fombonne E. (1992) Diagnostic assessment in a sample of autistic and developmentally impaired adolescents. Fournal of Autism and Developmental Disorders 22, 563-8I.

Frith U. (1989) Autism. Explaining the Enigma. Blackwell, Oxford.

Frith U. (2002) Autism. Explaining the Enigma, 2nd edn. Blackwell, Oxford.

Ghaziuddin M. (2000) Autism in mental retardation. Current Opinion in Psychiatry 13, 48I-4.

Hill E. L. \& Frith U. (2003) Understanding autism: insights from mind and brain. Philosophical Transactions of the Royal Society of London B 358, 387-92.

Jordan R. (200I) Autism with Severe Learning Difficulties. Souvenir Press, London.

Kraijer D. (1997) Autism and Autistic-Like Conditions in Mental Retardation. Swets \& Zeitlinger, Lisse.

Kraijer D. (2000) Review of adaptive behavior studies in mentally retarded persons with autism/pervasive developmental disorder. Fournal of Autism and Developmental Disorders 30, 39-47.

Light J. C., Roberts B., Dimarco R. \& Greiner N. (1998) Augmentative and alternative communication to support receptive and expressive communication for people with autism. Fournal of Communication Disorders 31, I53-80.

Lord C. \& Paul R. (1997) Language and communication in autism. In: Handbook of Autism and Pervasive Developmental Disorders, edition 2nd edn (eds D. Cohen \& F. Volkmar), pp. I95-225. Wiley, New York.

Lord C., Pickles A., McLennan J., Rutter M., Bregman J., Folstein S., Fombonne E., Leboyer M. \& Minshew N. (1997) Diagnosing autism: analyses of data from the autism diagnostic Interview. Fournal of Autism and Developmental Disorders 27, 50I-I7.

Noens I. \& Van Berckelaer-Onnes I. A. (2002) In OTHER Words; Augmentative Communication for Children with Learning Difficulties. Video and Brochure. University of Leiden, Leiden.

Noens I. \& Van Berckelaer-Onnes I. A. (2004) Making sense in a fragmentary word: communication in people with autism and learning disability. Autism 8, I97-2 I8.
Noens I. \& Van Berckelaer-Onnes I. A. (2005) Captured by details: sense-making, language and communication in autism. Fournal of Communication Disorders 38, I23-4I.

Nunnally J. C. \& Bernstein I. H. (1994) Psychometric Theory, 3 rd edn. Mc Graw-Hill, New York.

Prizant B. M. \& Schuler (1987) Facilitating communication: theoretical foundations. In: Handbook of Autism and Pervasive Developmental Disorders (eds D. Cohen \& A. Donnellan), pp. 316-32. Wiley, New York.

Schuler A. L., Prizant B. M. \& Wetherby A. (1997) Enhancing language and communication development: prelinguistic approaches. In: Handbook of Autism and Pervasive Developmental Disorders, edition 2nd edn (eds D. Cohen \& F. Volkmar), pp. 539-7I. Wiley, New York.

Stevens J. P. (1992) Applying Multivariate Statistics for the Social Sciences, 2nd edn. Erlbaum, Hillsdale, NJ.

Van Berckelaer-Onnes I. A. (I996) Autistisch en verstandelijk gehandicapt: dubbel gehandicapt [Autistic and learning disabled: a double handicap]. Nederlands Tijdschrift Voor de Zorg Aan Verstandelijk Gehandicapten 22, 7990.

Verpoorten R. A. W. (1996) Communicatie met verstandelijk gehandicapte autisten: een multidimensioneel communicatiemodel [Communication with learning disabled people with autism: a multidimensional communication model]. Nederlands Tijdschrift Voor Zorg Aan Verstandelijk Gehandicapten 22, 106-20.

Verpoorten R., Noens I. \& Van Berckelaer-Onnes I. A. (2004) The ComVoor - Voorlopers in Communicatie. Handleiding [The ComFor - Forerunners in Communication. Manual]. PITS, Leiden.

Verpoorten R., Noens I. \& Van Berckelaer-Onnes I. A. (in press.) ComFor - Forerunners in Communication. Manual.

Wetherby A. M., Prizant B. M. \& Schuler A. L. (2000) Understanding the nature of communication and language impairments. In: Autism Spectrum Disorders. A Transactional Perspective. Communication and Language Intervention Series, Vol. 9 (eds A. M. Wetherby \& B. M. Prizant), pp. I09-4I. Brookes, Baltimore, MD.

Willems J. B. H. G. (I996) Kijk op communicatie: constructie van een meetinstrument voor communicatie van mensen met een verstandelijke handicap [View on communication: construction of an instrument for communication of people with learning disability]. Unpublished Doctoral Dissertation. Katholieke Universiteit Brabant, Tilburg.

Willems J. \& Verpoorten R. (I996) Communicatie Profiel-Z. Handleiding [Communication Profile-Z. Manual]. Swets \& Zeitlinger, Lisse.

World Health Organization (1994) International Classification of Diseases, Ioth edn. World Health Organization, Geneva.

Accepted 8 November 2005 


\section{Appendix}

Structure of the ComFor

\begin{tabular}{|c|c|c|c|c|}
\hline \multicolumn{3}{|c|}{$\begin{array}{c}\text { LEVEL I: } \\
\text { PRESENTATION }\end{array}$} & \multicolumn{2}{|c|}{$\begin{array}{c}\text { LEVEL 2: } \\
\text { REPRESENTATION }\end{array}$} \\
\hline Series I & Series 2 & Series 3 & Series 4 & Series 5 \\
\hline & & $\begin{array}{l}17 \\
16\end{array}$ & & \\
\hline & & I5 & & 30 \\
\hline & 7 & I4 & & 29 \\
\hline D & 6 & I3 & & 28 \\
\hline C & 5 & I2 & 22 & 27 \\
\hline B & 4 & II & $2 \mathrm{I}$ & 26 \\
\hline $\mathrm{A}_{3}$ & 3 & I0 & 20 & 25 \\
\hline $\mathrm{A}_{2}$ & 2 & 9 & I9 & 24 \\
\hline AI & I & 8 & 18 & 23 \\
\hline
\end{tabular}

Series I: Assembling objects (so-called learning series)

Series 2: Sorting objects

Series 3: Sorting pictures

Series 4: Sorting within one form

Series 5: Sorting with different forms 